\title{
Review on Chromobacterium Violaceum, a Rare but Fatal Bacteria Needs Special Clinical Attention
}

\author{
*S Sharmin ${ }^{1}$, SMM Kamal ${ }^{2}$
}

\begin{abstract}
Chromobacterium violaceum is isolated from soil and water in tropical and subtropical areas. This Gram negative, capsulated, motile bacillus is considered as a saprophyte but occasionally it can act as an opportunistic pathogen for animals and human. It causes skin lesion with liver and lung abscesses, pneumonia, gastrointestinal tract infections, urinary tract infections, osteomyelitis, meningitis, peritonitis, endocarditis, respiratory distress syndrome and septic shock. Increasing reported cases with Chrombacterium violaceum infection has been noticed in recent decades. It should be considered for its difficult-to-treat entity characterized by a high frequency of sepsis, distantant metastasis, multidrugresistance and relapse. High mortality rate associated with this infection necessitate prompt diagnosis and appropriate antimicrobial therapy.
\end{abstract}

Key Words: Chromobacterium Violaceum, saprophyte, opportunistic, multidrug-resistance.

\section{Introduction}

Chromobacterium violaceum belongs to the family Neisseriacea of $\beta$-Proteobacteria and was first described by Bergonzini in $1880 . .^{1}$ It is a Gram negative, heterotrophic, flagellated bacilli which lives in a variety of ecosystems in tropical and subtropical regions. ${ }^{2}$ C. violaceum is a facultative anaerobe which is oxidase and catalase positive. It grows optimally at $30-35^{\circ} \mathrm{C}$. It is a saprophyte found mainly in soil and water. It grows readily on different bacteriological culture media including nutrient agar, blood agar, MacConkey agar and Muller-Hinton agar at $35-37^{\circ} \mathrm{C}$ and produce smooth low convex colonies with a dark violet metallic sheen. ${ }^{3,4}$ Few details regarding morphology, physiology, biochemical characteristics of $C$. violaceum are presented in Table. ${ }^{15,6}$

One particular characteristic of this genus is the production of a water insoluble secondary metabolite violacein, a purple pigment for which the synthesis is regulated by quorum sensing. ${ }^{7}$ and is responsible for the violet colonies in the media.
Although non-pigmented strains have also been reported. ${ }^{8}$ Though not essential for growth and survival, violacein has been suggested to be a respiratory pigment, having antiparasitic, antibiotic, antiviral, immunomodulatory, analgesic, antipyretic and anticancer effects. It has no association with pathogenesis. ${ }^{9,}, 10$

Although $C$. violaceum has been recognized as the single species of the Chromobacterium genus for a long time, nine novel species have been proposed since 2007: C. subtsugae, ${ }^{11}$ C. aquaticum, ${ }^{12} \mathrm{C}$. haemolyticum, ${ }^{13} \mathrm{C}$. piscinae, ${ }^{14} \mathrm{C}$. pseudoviolaceum, ${ }^{14}$ C. vaccinii, ${ }^{15} \mathrm{C}$. amazonense, ${ }^{16} \mathrm{C}$. alkanivorans, ${ }^{17}$ and C. rhizoryzae. ${ }^{18}$ Most of the Chromobacterium species were isolated from environmental samples (mainly from water, soil, and rhizosphere) and have not yet been associated with human infections. Exceptions include C. violaceum, isolated from both environmental and clinical samples and associated with several cases of fatal infections. ${ }^{19}$ and C. haemolyticum, isolated from a patient's sputum

\footnotetext{
${ }^{1}$ Dr. Sadia Sharmin, Associate Professor, Dept of Microbiology, Anwer Khan Modern Medical College

${ }^{2}$ Prof. S. M. Mostofa Kamal, Dept of Microbiology, Anwer Khan Modern Medical College

*Corresponding Author

Date of submission: 18.02.2019 Date of acceptance: 30.04 .2019
}

AKMMC J 2019; 10(2) : 169-175 
culture. ${ }^{13}$ and associated with a human case of bacteremia. ${ }^{20}$ The non-purple species of this genus are C. aquaticum, C. haemolyticum, C. alkanivorans and $\mathrm{C}$. rhizoryzae.

Table 1: Microbiological properties of C. violaceum. 5,6

\begin{tabular}{|c|c|}
\hline Properties & Description \\
\hline 1. Size & $(0.6-0.9 \times 1.5-3.0) \mathrm{mm}$ \\
\hline 2. Shape & Rods with rounded end \\
\hline 3. Capsule & Always capsulated \\
\hline 4. Motility & $\begin{array}{l}\text { Motile by means of a single polar } \\
\text { flagellum }\end{array}$ \\
\hline 5. Growth at $40 \mathrm{C}$ & - \\
\hline 6. Growth at $370 \mathrm{C}$ & + \\
\hline 7. Growth at $\mathrm{pH} 4$ & + \\
\hline 8. Growth at $\mathrm{pH} 3$ & - \\
\hline 9. Growth in $2 \% \mathrm{NaCl}$ & + \\
\hline 10. Growth in $4 \% \mathrm{NaCl}$ & - \\
\hline 11. Anaerobic growth & + \\
\hline 12. Fermentation of glucose & + \\
\hline 13. Cyanide production & + \\
\hline $\begin{array}{l}\text { 14. Lecithinase production } \\
\text { (Turbid zone on egg yolk agar) }\end{array}$ & + \\
\hline
\end{tabular}

15. Acid production from

L-arabinose

Trehalose

D-galactose

Gluconate

D-maltose

$\mathrm{N}$-acetyl glucosamine

16. Lactate utilization

17. Casein hydrolysis

$+$

18. Esculin hydrolysis

'-' and '+' respectively indicates absence and presence

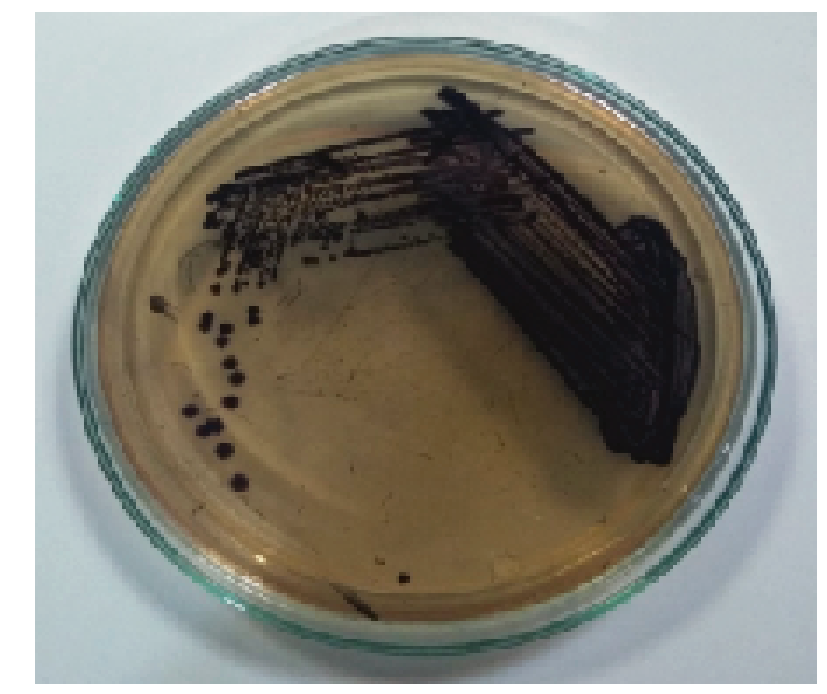

Figure 1: violet-pigmented colonies on the MacConkey agar media after 24 hours of incubation, typical of $C$. violaceum isolated in Microbiology lab of Anwer Khan Modern Medical College.

\section{Clinical Reports}

Though $C$. violaceum is primarily considered to be an environmental organism, not regularly associated with human infections, sporadic cases on its involvement in human infections have been reported. Its pathogenic potential was first described by Woolley in 1905, when he isolated it from a fatal infection in a buffalo. ${ }^{21}$ and the first case in humans was reported from Malaysia in 1927. 22 Cases of $C$. violaceum infection in humans have been reported from Australia, India, Nepal, USA, Brazil, and Congo. ${ }^{23-31}$

There have been about 150 cases reported worldwide. ${ }^{4}$ and mortality rate in such cases is found to be high (53\%). ${ }^{19}$ Recently the first case of C. violaceum infection has been reported from Bangladesh. ${ }^{32}$ Also recently, the first case of $C$. violaceum infection in Cambodia was reported in a child who recovered after antibiotic treatment ${ }^{33}$ and cases of infection by this bacterium were also reported in Taiwan, ${ }^{34}$ Malaysia, ${ }^{35}$ and Vietnam. ${ }^{36}$ Recently, the first case of fatal adult bacteremia caused by $C$. violaceum was reported in Africa. ${ }^{9}$

C. violaceum infection is reported to be fatal, whenever it occurs in human subjects, and it is being 
considered as an emergent pathogen. $37,38,39$ Age of patients in this review ranges from 11 months to 73 years. Specimens from these patients used for diagnosis include blood, urine, pus sample, and swab from the oropharynx. $C$. violaceum can also cause infections in animals and there are reported cases in pigs, monkeys, sheep and dogs. $40,41,42,43$

\section{Pathogenesis and Pathology}

The route of entry of $C$. violaceum still remains unclear. Most patients have a history of trauma or wounds which have been contaminated with soil or stagnant water. In some cases the injury may be so mild that it may not be recalled by the patient. ${ }^{44}$ Infection via an oral route is suspected in patients with diarrhea. Unusual routes of exposure include scuba diving or near drowning, swimming, wading in water, falling or playing in muddy water and following surgical procedures. ${ }^{45,46,47}$ Despite low infectivity, $C$. violaceum is considered an opportunistic pathogen and its infection has a tremendous public health impact due to the mortality rate in humans and animals ${ }^{48,49}$ which justifies the study of its pathogenicity. But its pathogenesis is not yet clear.

In 1988, Miller and colleagues conducted a study that compared virulent and avirulent strains of $C$. violaceum, in which virulent strains had elevated levels of superoxide dismutase and catalase that may protect the microorganism from phagocytic attack in humans, possibly leading to its extreme virulence. ${ }^{50}$ The genome sequence of $C$. violaceum ATCC 12472 demonstrated the presence of different pathogenic factors. ${ }^{51}$ Miki et al demonstrated that a type III secretion system (T3SS) encoded by genes present in the Chromobacterium pathogenicity islands 1 and 1a (Cpi-1/-1a) is involved with cytotoxicity that causes damage to hepatocytes and promotes the invasion of nonphagocytic cell. The CilA is a regulator of the T3SS and the effector protein CopE has been characterized as a guanine nucleotide exchange factor (GEFs) involved in epithelial cell invasion. ${ }^{52}$ Two recent works studied the protein secreted by $C$. violaceum into the culture medium, using mass spectrometry (MS). ${ }^{53,} 54$ These works identified proteins potentially associated with virulence such as hemolysin, outer membrane proteins, collagenase, flagellar protein, metallopeptidases and type VI secretion system (T4SS) effector protein. The role of these proteins in pathogenicity remains to be determined.

Most of the patients had a short incubation time. The most common symptoms of $C$. violaceum infections were fever, pain over the infected site associated with various skin lesions, abdominal pain, abscesses in various organs like liver, skin, lungs, lymph nodes and brain and rapid progression to sepsis. ${ }^{31,47,55}$ It is also worth noting that the clinical symptoms of $C$. violaceum infection may not occur immediately after specific exposure to water or soil; instead, they may occur 60 days after exposure. The clinical spectrum of $C$. violaceum infection includs urinary tract infection, pneumonia, gastrointestinal infection, localized cutaneous lesions, localized or metastatic abscesses, osteomyelitis, meningitis, peritonitis, brain abscess, endocarditis, hemophagocytic syndrome, respiratory distress syndrome and fulminant sepsis.

Infection is reported to be severe in malnourished and immunocompromised Patients. ${ }^{56}$ Infection occurs fast and thus, a rapid diagnosis and antibiotic susceptibility profile determination are of paramount importance. ${ }^{36}$ There have been reports that $C$. violaceum septicemia occurs more commonly in patients with chronic granulomatous disease, neutrophil dysfunction, and severe polymorphonuclear G6PD deficiency. ${ }^{57,58}$ In these conditions, polymorphonuclear leucocytes and monocytes lack the ability to produce oxygen metabolites required to kill phagocytised bacteria ${ }^{59}$ which renders the patient susceptible to develop septicemia and dissemination of infection to multiple organs. Moreover, virulent strains of $C$. violaceum can produce an endotoxin that withstands attack from phagocytic cells. The rapid progression of this infection and the high fatality rate prevents evaluation for these underlying immunodeficiencies in most cases. It is possible that occult microabscess or hidden septic focus may persist in a patient's internal organs despite adequate treatment. Therefore, it is necessary to treat patients with $C$. violaceum infection for an extended period and maintain close follow-up procedures.

The isolation of $C$. violaceum from water sampled in a hospital and the description of hospital-acquired 
infections indicated the potential of this bacterium to cause nosocomial infections. ${ }^{60,61}$ One study for neonatal sepsis conducted by Anah and others in 2008 had demonstrated isolation of $C$. violaceum from 10 neonates $(6.3 \%){ }^{62}$ These data indicate that this microorganism might have existed in hospital settings and this warrants attention. Rapid progression to life-threatening sepsis associated with metastatic abscess in $C$. violaceum infection is the most striking feature.

Laboratory data are nonspecific in $C$. violaceum infection; however, an abnormal hemogram with leukocytosis, leukopenia or left shift may occur. ${ }^{19}$ Diagnosing $C$. violaceum infection is currently based on a culture of clinical specimens followed by subsequent biochemical identification. There are no available serological tests. In 2006, Scholz and colleagues developed a method for detecting $C$. violaceum by multiplex polymerase chain reaction but it has not been widely accepted yet. ${ }^{63}$

\section{Antimicrobial Susceptibility}

Data on antimicrobial susceptibility of $C$. violaceum remain very limited because this pathogen is rarely isolated from clinical specimens and results of susceptibility testing vary in different clinical settings. The Clinical and Laboratory Standards Institute has not yet established minimum inhibitory concentration (MIC) associated with $C$. violaceum. It is found to be extremely resistant to penicillins and cephalosporins. ${ }^{64}$ In 1988, Aldridge and others conducted another study to compare the in vitro activity of ciprofloxacin and other antimicrobial agents against clinical strains of $C$. violaceum. The effective agents of $C$. violaceum including ticarcillin, carbenicillin, and cefoxitin, which were reported in $1976 .{ }^{65}$ Before 1990, the usual treatment for $C$. violaceum infection was chloramphenicol, trimethoprim-sulfamethoxazole, tetracycline or aminoglycosides. However, several new potent antimicrobials that were introduced after 1990 include fluoroquinolone and carbapenem as penicillins and cephalosporins are extremely resistant due to increased beta-lactamase activity in C. violaceum. According to study by Aldridge, ciprofloxacin was the most active drug to combat $C$. violaceum. Actually combination therapy with a regimen of chloramphenicol, beta-lactams, trimethoprim-sulfamethoxazole or fluoroquinolones along with one of the aminoglycosides is the drug of choice. An extensive treatment period of parenteral antimicrobials for 2 to 4 weeks for $C$. violaceum infection followed by maintenance therapy with an oral agent such as trimethoprim-sulfamethoxazole, tetracycline, or fluoroquinolone for 2 to 3 months to prevent relapse is recommended.57,66,67,68 Therefore, it is important for physicians to be aware of $C$. violaceum infection and its appropriate antimicrobial treatment regimen.

In conclusion, $C$. violaceum infection may become an emergent infection with fatal outcome after further global climate change. It represents a difficult-to-treat entity, so special attention is required. Very prompt diagnosis, optimal antimicrobial therapy and adequate therapeutic duration for $C$. violaceum infection are the keys for successful outcome.

\section{Conflict of interest: None.}

\section{References}

1. Sneath PHA. Genus Chromobacterium Bergonzini 1881, 153AL, In NH Krieg, JG Holt eds., Bergey's Manual of Systematic Bacteriology; 1984, Vol. 1, p. 580-582.

2. Hungria $M$, Nicolás MF, Guimarães $C T$, Vasconcelos ATR. Tolerance to stresses and environmental adaptability of Chromobacterium violaceum. Genet Mol Res; 2004, 3: 102-116.

3. Howard A. J and Ison C. A. "Haemophilus, Gardnerella and other bacilli," in Mackie and McCartney Practical Medical Microbiology, J. G. Collee, A. G. Fraser, B. P. Marmion, and A. Simmons, Eds., pp. 329-341, Churchill Livingstone, New York, NY, USA, 14th edition, 1996.

4. Ray P, Sharma J, Marak R. S. K et al., "Chromobacterium violaceum septicaemia from north India," Indian Journal of Medical Research; 2004, vol. 120, no. 6: pp. 523-526.

5. Gills M, Ley JD. The genera Chromobacterium and Janthiobacterium. In: Dworkin M, Falkow S, Rosenberg E, Schleifer KH, Stackebrandt E, editors. The Prokaryotes. $3^{\text {rd }}$ ed., vol. 5. Singapore: Springer; 2006, p. 738. 
6. Gills M, Logan LA. Genus IV Chromobacterium. In: Brenner DJ, Krieg NR, Staley JT, editors. vol. 2. Bergey's manual of systematic bacteriology. $2^{\text {nd }}$ ed. New York: Springer; 2005, p. 827.

7. Mcclean K. H, Winson M. K, Fish L, et al. Quorum sensing and Chromobacterium violaceum: exploitation of violacein production and inhibition for the detection of $\mathrm{N}$-acyl homoserine lactones. Microbiology; 1997, 143: 3703-3711.

8. Sivendra R and Tan, S. H. Pathogenicity of nonpigmented cultures of Chromobacterium violaceum. J. Clin. Microbiol; 1977, 5: 514-516.

9. Durán, N, Justo G. Z, Durán M, et al. Advances in Chromobacterium violaceum and properties of violacein-its main secondary metabolite: a review. Biotechnol. Adv; 2016, 34: 1030-1045.

10. Durán N, Justo G. Z, Ferreira C. V, et al. Violacein: properties and biological activities. Biotechnol. Appl. Biochem; 2007, 48: 127-133.

11. Martin P. A, Gundersen-Rindal D, Blackburn M, and Buyer J. Chromobacterium subtsugae sp. nov., a betaproteobacterium toxic to Colorado potato beetle and other insect pests. Int. J. Syst. Evol. Microbiol; 2007, 57: 993-999.

12. Young C. C, Arun A. B, Lai W. A, et al. Chromobacterium aquaticum sp. nov., isolated from spring water samples. Int. J. Syst. Evol. Microbiol; 2008, 58: 877-880.

13. Han X. Y, Han F. S and Segal J. Chromobacterium haemolyticum sp. nov., a strongly haemolytic species. Int. J. Syst. Evol. Microbiol; 2008, 58: 1398-1403.

14. Kämpfer P, Busse H. J and Scholz H. C. Chromobacterium piscinae sp. nov. and Chromobacterium pseudoviolaceum sp. nov, from environmental samples. Int. J. Syst. Evol. Microbiol; 2009, 59: 2486-2490.

15. Soby S. D, Gadagkar S. R, Contreras C, et al. Chromobacterium vaccinii sp. nov, isolated from native and cultivated cranberry (Vaccinium macrocarpon Ait.) bogs and irrigation ponds. Int. J. Syst. Evol. Microbiol; 2013, 63: 1840-1846.
16. Menezes C. B, Tonin M. F, Corrêa, D. B, et al. Chromobacterium amazonense sp. nov. isolated from water samples from the Rio Negro, Amazon, Brazil. Antonie Van Leeuwenhoek; 2015, 107: 1057-1063.

17. Bajaj A, Kumar A, Yadav S, et al. Isolation and characterization of a novel Gram-negative bacterium Chromobacterium alkanivorans sp. nov., strain IITR-71T degrading halogenated alkanes. Int. J. Syst. Evol. Microbiol; 2016, 66: 5228-5235.

18. Zhou S, Guo X, Wang H, et al. Chromobacterium rhizoryzae sp. nov., isolated from rice roots. Int. J. Syst. Evol. Microbiol; 2016, 66: 3890-3896.

19. Yang C. H and Li Y. H. Chromobacterium violaceum infection: a clinical review of an important but neglected infection. J. Chin. Med. Assoc; 2011, 74: 435-441.

20. Okada $\mathrm{M}$, Inokuchi $\mathrm{R}$, Shinohara $\mathrm{K}$, et al. Chromobacterium haemolyticum-induced bacteremia in a healthy young man. BMC Infect. Dis; 2013, 13: 406.

21. Woolley PG. Bacillus violaceous manila, a pathogenic organism. Bull John Hopkins Hosp; 1905, 16: 89-93.

22. Sneath PH, Whelan JP, Bhagwan Singh R, et al. Fatal infection by Chromobacteriumviolaceum. Lancet; 1953, 265: 276-277.

23. Meher-Homji Z, Mangalore RP, Johnson PD, et al. Chromobacterium violaceum infection in chronic granulomatous disease: a case report and review of the literature. JMM Case Rep 2017; 4(1)

24. Vincent DP, Meghana CG, Mohan V, et al. Chromobacterium violaceum causing communityacquired urinary tract infection. Indian J Health Sci Biomed Res K; 2017, 10(1): 97-99.

25. Parajuli NP, Bhetwal A, Ghimire S, et al. Bacteremia caused by a rare pathogen Chromobacterium violaceum: a case report from Nepal. Int J Gen Med; 2016, 9: 441.

26. Kaniyarakkal V, Orvankundil S, Lalitha SK, et al. Chromobacterium violaceum septicaemia and urinary tract infection: case reports from a tertiary care hospital in South India. Case Rep Infect Dis; 2016, 2016: 6795743. 
27. Balaraman L, Shanmugham M, Sathyabhama MC. Chromobacterium violaceum causing catheter-related blood stream infection. J Acad Clin Microbiol; 2016, 18(1): 47-49.

28. Ansari S, Paudel P, Gautam K, et al. Chromobacterium violaceum isolated from a wound sepsis: a case study from Nepal. Case Rep Infect Dis 2015; 2015: 181946;

29. Richard KR, Lovvorn JJ, Oliver SE, et al. Chromobacterium violaceum sepsis: rethinking conventional therapy to improve outcome. Am J Case Rep; 2015, 16: 740-744.

30. Fernandes MJDBC, Luz KG, Dantas LDA, et al. Chromobacterium violaceum: a fatal case in the northeast of the Brazil. J Bras Patol Med La; 2014, 50(4): 278- 279.

31. Kar H, Mane V, Urhekar AD, et al. A first case report in tertiary care hospital, Navi Mumbai, India Chromobacterium violaceum septicaemia in a child. Int $\mathrm{J}$ Curr Microbiol Appl Sci; 2013, 2(7): 245-249.

32. Sharmin S, Akter Jahan A, Kamal S.M.M, et al. Fatal Infection Caused by Chromobacterium violaceum: A Case Report from a Tertiary Care Hospital in Bangladesh. Case Reports in Infectious Diseases; 2019.

33. Ke L An, K P Heng, S Riley, et al. Paediatric Chromobacterium violaceum in Cambodia: the first documented case. Trop. Dr; 2004, 42: 178-1

34. Yang $\mathrm{C}$, Jiang $\mathrm{P}$, Xiao $\mathrm{S}$, et al. Fed-batch fermentation of recombinant Citrobacter freundii with expression of a violaceinsynthesizing gene cluster for efficient violacein production from glycerol. Biochem. Eng. J; 2011, 57: 55-62.

35. Cheong, B.M.K. A fatal case of pulmonary Chromobacterium violaceum infection in an adult. Med. J. Malaysia; 2010, 65: 148-149.

36. Campbell J.I, Lan N.P.H, Qui P.T, et al. A successful antimicrobial regime for Chromobacterium violaceum induced bacteremia. BMC Infect. Dis; 2013, 13: 4.

37. Chattopadhyay A, Kumar V, Bhat N, et al. Chromobacterium violaceum infection: a rare but frequently fatal disease. J Pediatr Surg 2002; 37(1): 108-110.
38. Swain B, Otta S, Sahu K, et al. Urinary tract infection by Chromobacterium violaceum. J Clin Diagn Res; 2014, 8(8):

39. Bottieau E, Mukendi D, Kalo J-R, et al. Fatal Chromobacterium violaceum bacteraemia in rural Bandundu, Democratic Republic of the Congo. New Microbe New Infect; 2015, 3: 21-23.

40. Kumar, M., Chaturvedi, V.K., and Singh, D.P., Chromobacterium violaceum, an unusual pathogen of swine, Indian Veter. J; 1999, 76,869-871.

41. Kornegay R.W, Pirie, G, Brown C.C and Newton J.C. Chromobacteriosis (Chromobacterium violaceum) in a 3 colobus monkeys (Colobus polykomos), J. Zoo Wildflife Med; 1991, 22, 476-484.

42. Turner S.J, Lewis G.D, Saul D.J, et al, Chromobacterium violaceum $16 \mathrm{~S}$ ribosomal RNA gene, partial sequence spanning the V3V4 regions, NCBINucleotide. U65966, 1996.

43. Gogolewski R.P. Chromobacterium violaceum septicemia in a dog, Austr. Veter. J; 1983, 60: 226- 226.

44. Hassan H, Suntharalingam S, Dhillon KS. Fatal Chromobacterium violaceum septicemia. Singapore Med J; 1993, 34: 456-458.

45. Starr AJ, Cribbett LS, Poklepovc J, et al. Chromobacterium violaceum presenting as a surgical emergency. South Med J; 1981, 74: 1137-1139.

46. Victorica B, Baer H, Ayoub EM. Successful treatment of systemic Chromobacterium violaceum infection. JAMA; 1974, 230: 578580 .

47. Chen $\mathrm{CH}$, Lin LC, Liu CE, et al. Chromobacterium violaceum bacteremia: a case report. J Microbiol Immunol Infect; 2003, 36: 141-144.

48. Rai R, Karnaker V.K, Shetty V, et al. Chromobacterium violaceum septicaemia-a case report. Al Ameen J. Med; 2011, Sci. 4: 201203.

49. Liu D.X, Didier P.J, Plauche G.B. Chromobacterium violaceum infections in 13 nonhuman primates. J. Med. Primatol; 2012, 41: $107-114$. 
50. Miller DP, Blevins WT, Steele DB, et al. A comparative study of virulent and avirulent strains of Chromobacterium violaceum. Can J Microbiol; 1988, 34: 249.

51. Brazilian National Genome Project Consortium. The complete genome sequence of Chromobacterium violaceum reveals remarkable and exploitable bacterial adaptability. Proc. Natl. Acad. U. S. A. 100; 2003, 11660-11665.

52. Miki $\mathrm{T}$, Akiba $\mathrm{K}$, Iguchi $\mathrm{M}$, et al. The Chromobacterium violaceum type III effector Cop E, a guanine nucleotide exchange factor for Rac1 and Cdc42, is involved in bacterial invasion of epithelial cells and pathogenesis. Mol. Microbiol; 2011, 80: 1186-1203.

53. Ciprandi A, da Silva W.M, Valadares Santos A.V, et al. Chromobacterium violaceum: important insights for virulence and biotechnological potential by exoproteomic studies. Curr. Microbiol; 2013, 67: 100-106.

54. Castro-Gomes, T Cardoso M. S, Da Rocha W.D, et al. Identification of secreted virulence factors of Chromobacterium violaceum. J. Microbiol; 2014, 52: 350-353.

55. Orsetti A.G, Markiewicz P, Epstein M.G, et al. Liver abscesses by Chromobacterium violaceum: a case report of a rare disease. OA Case Rep; 2013, 2: 19.

56. Rashid Z, Ali U, Sulong A, et al. Chromobacterium violaceum infections; a series of case reports in a Malaysian tertiary hospital. Internet J. Infect. Dis; 2013, 11: 1 .

57. Sirinavin S, Techasaensiri C, Benjaponpitak S, Pornkul R, and Vorachit M. Invasive Chromobacterium violaceum infection in children: case report and review. Pediatr Infect Dis J; 2005, 24: 559-561.

58. Mamlok RJ, Mamlok V, Mills GC, et al. Glucose-6-phosphate dehydrogenase deficiency, neutrophil dysfunction and Chromobacterium violaceum sepsis. J Pediatr; 1987, 111: 852854.
59. Ponte R and Jenkins SG. Fatal Chromobacterium violaceum infections associated with exposure to stagnant water. Pediatr Infect Dis J; 1992, 11: 583-586.

60. Umadevi S, Kumar S, Stephen S, et al. Chromobacterium violaceum: a potential nosocomial pathogen. Am. J. Infect. Control; 2013, 41: 386-388.

61. Hagiya H, Murase $T$, Suzuki $M$, et al.Chromobacterium violaceum nosocomial pneumonia in two Japanese patients at anintensive care unit. J. Infect. Chemother; 2014, 20: 139-142.

62. Anah MU, Udo JJ, Ochigbo SO, et al. Neonatal septicemia in Calabar, Nigeria. Trop Doct; 2008, 38: 126 to 8 .

63. Scholz HC, Witte A, Tomaso $\mathrm{H}$, et al. Detection of Chromobacterium violaceum by multiplex PCR targeting the prgl, spaO, invG, and sipB genes. Syst Appl Microbiol; 2006, 29: 45-8.

64. Farrar WE, O'Dell NM. b-lactamase activity in Chromobacterium violaceum. J Infect Dis 1976; 134: $290-3$

65. Aldridge KE, Valaninis GT, Saners CV. Comparison of the in vitro activity of ciprofloxacin and 24 other antimicrobial agents against clinical strains of Chromobacterium violaceum. Diagn Microbiol Infect Dis; 1988, 10: $31-9$.

66. Patterson RH, Banister GB, Knight V. Case reports: Chromobacterial infection in man. Arch Int Med; 1952, 90: 79-86.

67. Petrillo VF, Severo V, Santos MM, et al. Recurrent infection with Chromobacterium violaceum: first case report from South America. J Infect 1984; 9: 167 to 9.

68. Jitmuang A. Human Chromobacterium violaceum infection in Southeast Asia: case reports and literature review. South Asian J Trop Med Public -Health 2008; 39: 452 to 60 . 